\title{
The Effects of the 5-step Method for Infant Cardiopulmonary Resuscitation Training on Nursing Students' Knowledge, Attitude, and Performance Ability
}

\author{
Jin Young Kim ${ }^{1}$, Hye Young Ahn ${ }^{2}$ \\ ${ }^{1}$ Assistant Professor, Department of Nursing, Seoyeong University, Gwangju; ${ }^{2}$ Professor, College of Nursing, Eulji University, Daejeon, Korea
}

Purpose: The purpose of this study was to examine the effects of an infant cardiopulmonary resuscitation (CPR) training program that applied the 5-step method on the knowledge, attitudes, and performance ability of nursing students in terms of enhancement and sustainability. Methods: Sixty-one nursing students (28 in the experimental group and 33 in the control group) from D city participated in this study. Data were collected from April 25 to December 15, 2016. The experimental group and control group received infant CPR education using the 5-step method and the traditional method, respectively. The outcome variables were measured 3 times (pretest and posttest at 1 week and 6 months after training) Results: There were significant differences in attitude $(\mathrm{t}=2.68, p=.009)$ and performance ability $(\mathrm{t}=4.56, p<.001)$ between the groups at 1 week after training, as well as in sustained performance ability at 6 months after training $(\mathrm{F}=6.76, p=.012)$. Conclusion: The 5-step method of infant $\mathrm{CPR}$ training was effective for improving performance ability in a sustained manner and promoting a positive attitude. Therefore, it is recommended that nursing students, as infant CPR novices, receive training using this effective method.

Key words: Cardiopulmonary resuscitation; Infant; Education

\section{Corresponding author Hye Young Ahn}

https://orcid.org/0000-0002-5353-671X

College of Nursing, Eulji University,

771-77, Gyeryong-ro, Joong-gu, Daejeon 34824, Korea

TEL +82-42-259-1715 FAX +82-42-259-1709

E-MAIL ahanaya@eulji.ac.kr

*This article was adapted from a dissertation by Jin Young Kim in partial fulfillment of the requirements for the doctoral degree at Eulji University.

Received Aug 28, 2018 Revised Oct 3, 2018 Accepted Oct 30, 2018 (a) This is an Open Access article distributed under the terms of the Creative Commons Attribution NonCommercial License (http://creativecommons.org/licenses/by-nc/4.0/) which permits unrestricted noncommercial use, distribution, and reproduction in any medium, provided the original work is properly cited.

\section{INTRODUCTION}

\section{Need for Study}

According to the Korean nationwide out-of-hospital cardiac arrest (OHCA) registry (2006-2007), infants show a significantly higher incidence of cardiac arrest than children and adolescents, but have the lowest rate of being discharged alive [1]. Although infants experience a lower incidence of cardiac arrest than adults, cardiac arrest in infants is an important issue that cannot be ignored. Although preventing cardiac arrest is important, it is also crucial for the first responder to give infant cardiopulmonary resuscitation (infant CPR), with the aim of increasing the survival rate and preventing neurological sequelae. What the medical staff is able to do in an emergency setting can be divided into 2 categories: identifying the patient's problems and solving those problems. The former involves clinical reasoning, while the latter requires performing skills to solve the problems. In particular, since there are limited chances to receive training for infant $\mathrm{CPR}$, effective educational strategies are needed to optimize learning outcomes [2]. In addition, since infant CPR is characterized by a greater loss of performance ability than knowledge with time [3], infant CPR education should focus on improving and 
maintaining performance ability. Professional institutions, including the American Heart Association (AHA), have recommended 'watching and repeating' a video as an essential method [4]. This method can be applied easily, and conveys knowledge of CPR, causes positive changes in attitude, and improves performance ability; however, it has limitations related to sustainability [5]. Additional methods include the immediate remediation method [6,7] and a video self-instruction program [8] for infant and child CPR. However, the effects of training differ depending on the subject and the educational method, and it is necessary to apply various educational methods for nursing students to determine which is most suitable.

Infants have different anatomical structures from those of adults, such as the airway, and experience different causes of cardiac arrest, which often involve respiratory failure that reduces the oxygen content in the blood even before the onset of arrest. For these reasons, it is impossible to apply adult CPR techniques to infants who are experiencing cardiac arrest. To perform infant CPR correctly, specific education is therefore necessary.

As CPR has become more important from a societal perspective since the late 2010s, nursing schools have designated $\mathrm{CPR}$ as a regular subject, making it a part of emergency nursing [9]. However, their training primarily focuses on adult CPR, to the point of almost excluding infant CPR [10]. In addition, universities have different educational infrastructures and experience some level of randomness in the administration of educational programs [10]. It is therefore necessary to develop a program that can improve and sustain performance ability, which is the most important learning goal, on the basis of improved knowledge of infant CPR and positive attitudes, taking the educational environment of nursing students into account.

Skills education is a psychomotor domain in pedagogy [11], for which the learning process was categorized into 5 steps by George and Doto [12]. In the first step of the 5-step method (overview), the educator motivates the learner to learn by presenting him/her with concepts and goals of the skills. In the second step (silent demonstration), the learner observes the full course of the skilled educator's demonstration. In the third step (demonstration with comment), the educator demonstrates the skill with comments for each step. During this process, the educator and the learner interact with each other through feedback. In the fourth step (verbalization), learners practice explaining the skill verbally. Through this step, learners acquire further knowledge and improve their understanding and memory [13]. In the fifth step (practice), learners practice the skill under the educator's direction, and any errors are corrected immediately to prevent the consolidation of incorrectly learned skills [14]. The 5-step method clearly presents the role of the educator, with explicit instructions at every stage in order to improve the educational environment. The 5-step method is composed of a detailed learning process that is facilitated by the role of the educator [12]. According to a previous study [15], the most important factor for enhancing the effectiveness of skill education is individual feedback and practice under supervision of the educator. Therefore, the 5step method is suitable to apply for infant CPR education among nursing students.

A literature review regarding the 5-step method found that it had the positive effects of improving performance ability and reducing the time needed to learn skills when it was applied to skill education for dental care students [16]. Teaching materials for peritoneal dialysis patients and their caregivers have been developed on the basis of the 5-step method and are expected to make peritoneal dialysis safer and more efficient for the patients when a nurse, who is the educator, uses these materials 3 [1]. Manual defibrillation training for medical students also involved the 5-step method, which resulted in learners being more satisfied with the educator's feedback and verbalization [17].

Since nursing students may gain experience responding to cases of infant cardiac arrest during their clinical practice, unlike general college students, it is possible for their knowledge and performance ability of infant CPR to be positively affected by receiving general knowledge related to infants and infant CPR training during their undergraduate studies. Moreover, CPR performance ability is positively correlated with knowledge and attitudes [18]. On this basis, the present study aimed to apply the 5-step method developed by George and Doto [12] to infant CPR education for nursing students and to measure its educational effects and sustainability, with knowledge, attitudes, and performance ability as variables.

\section{Objectives}

This study aimed to analyze the effects of an infant CPR training program that applied the 5-step method on nursing students' knowledge, attitudes, and performance ability, and to assess the sustainability of those effects.

\section{Hypotheses}

- The experimental group receiving infant CPR training with the 5-step method would show higher scores for knowledge, attitudes, and performance ability than the control group at 1 week after the training program.

- The experimental group receiving infant CPR training with the 5-step method would maintain higher scores for 
knowledge, attitudes, and performance ability than the control group at 6 months after the training program, indicating the sustainability (the variation between 1 week and 6 months after the training program) of its effects.

\section{METHODS}

\section{Study Design}

This was a quasi-experimental study using a non-equivalent control group non-synchronized design to analyze the effects of an infant CPR training program applying the 5-step method for nursing students.

\section{Subjects}

The proximate population of this study comprised juniors who were taking a lecture on pediatric nursing education at a university in D City, understood the purpose of this study, consented to participate, and had no CPR license. To mini- mize the diffusion effect, taking the participants' learning schedule into account, the first and second groups engaging in clinical practice for pediatric nursing in the former part of the course formed the control group and the third and fourth groups engaging in clinical practice in the latter part of the course formed the experimental group. The $\mathrm{G}^{*}$ Power Analysis 3.1 program [19] was used to estimate the sample size, and repeated-measures analysis of variance (ANOVA) (measuring 3 times repetitively) found a total minimum number of 46 persons, with an effect size of .40 [20], a significance level $(\alpha)$ of .05 , and testability (1- $\beta$ ) of .90 . Taking a dropout rate of $10 \%$ into account, the required sample size was estimated to be a total of 52, and this sample size was exceeded, with 30 participants in the experimental group and 33 in the control group. Two participants dropped out of the experimental group (1 for a personal reason [temporary absence from college] and 1 because of CPR license acquisition), yielding a total of 61 participants (28 in the experimental group and 33 in the control group) (Figure 1).

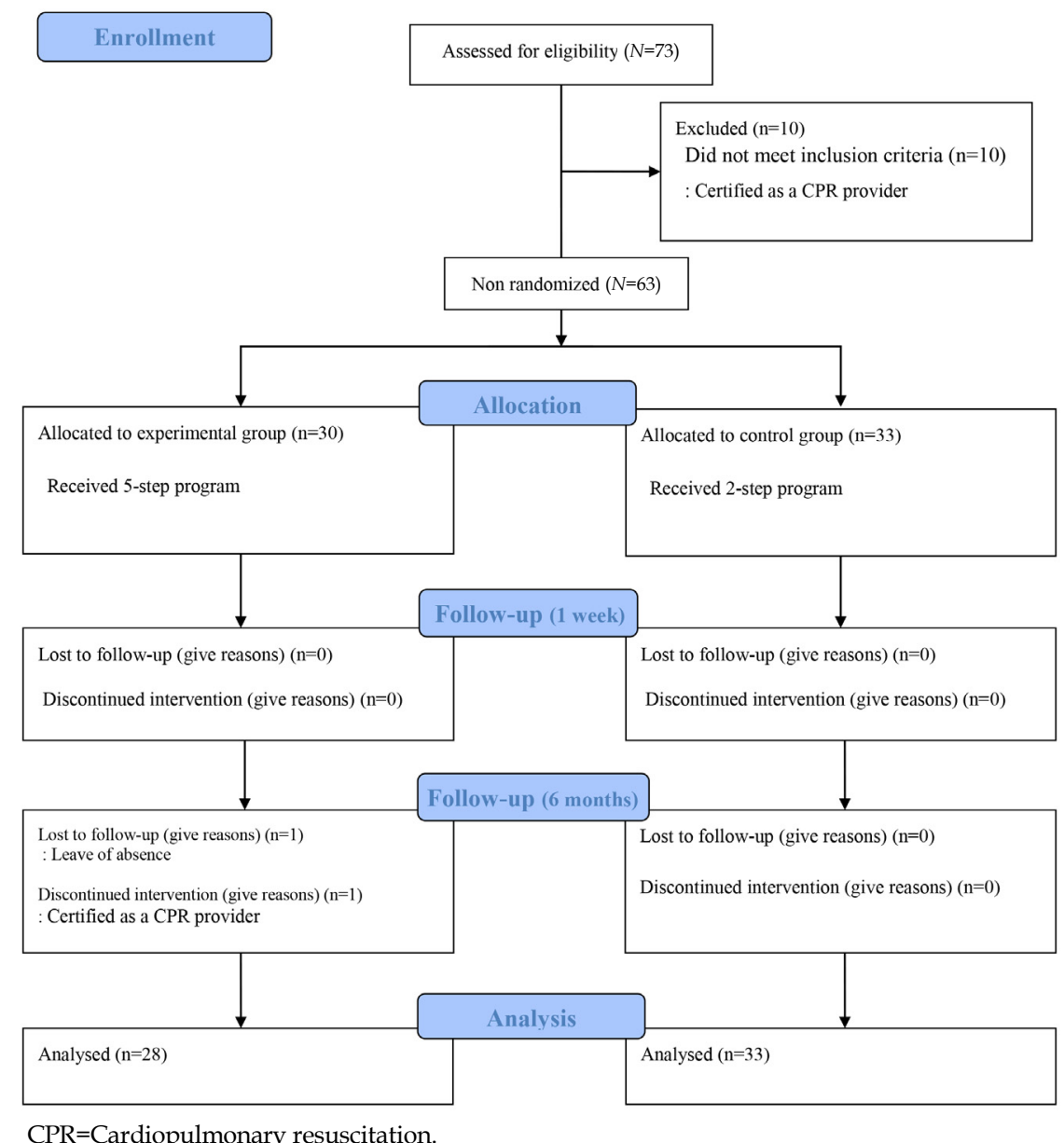

Figure 1. Process flow diagram. 


\section{Instruments}

\section{1) Knowledge of infant CPR}

To measure participants' knowledge of infant CPR, the researcher developed a set of 18 items appropriate for this study on the basis of the infant CPR items contained in the 2011 Korean Association of Cardiopulmonary Resuscitation (KACPR) guidelines [21]. Correct answers were scored as 1 and incorrect answers as 0 , with the response have no idea (scored as 0 ) added to prevent any predictive error; therefore, the scores ranged from 0 to 18 .

Preliminary research was conducted among 3 seniors at a nursing college to analyze the usability of the items; then, their difficulty and differentiation were analyzed according to classical test theory [22]. On the basis of preliminary research, 4 items with differentiation $<.20$, which is a criterion for revision or deletion, were revised after they were reviewed by the researcher and a professor of pediatric nursing. Then, a professor of pediatrics, 4 CPR instructors, and a professor of pediatric nursing with 15 years of career experience in pediatrics were asked to determine content validity. The mean Content Validity Index (CVI) was estimated to be .94 for all items by estimating the proportions of responses to a structured questionnaire using a 4-point scale [23].

\section{2) Attitudes toward infant CPR}

To measure attitudes toward CPR, Cho's [24] instrument developed for nurses was adapted by Park and Jeon [25]. It had 10 items for emotional factors on a 7-point Likert scale, as well as 3 items for belief factors and 3 items for behavioral factors on a 5-point scale. Although the existing tool scored belief and behavioral factors using a 4-point scale, it was revised to a 5-point scale to increase reliability [26]. Five items were analyzed through recoding. For emotional factors, the most positive response was scored 7 and the most negative response was scored 1, with the total scores ranging from 10 to 70 , and the scores for the belief and behavioral factors ranged from 5 to 15 , with 1 for 'totally disagree' and 5 for 'totally agree'. The higher the score, the more positive attitude toward infant CPR.

For reliability, Cronbach's $\alpha=.72$ in the study of Park and Jeon [25] and .65 in this study.

\section{3) Infant CPR performance ability}

A professor of emergency medicine, a professor of pediatric nursing, and an infant intensive care unit nurse with 15 years of career experience determined the content validity of the 2011 KACPR single-rescuer infant CPR skill checklist [21].

This instrument for measuring performance ability is composed of items regarding checking rescuer and patient safety, checking responses, emergency medical system activation, measuring the patient's pulse rate, checking the patient's position, chest pressure (position, depth, velocity, and resilience), securing the airway, and artificial breathing. To measure performance ability, the participants were asked to give infant CPR in 5 sessions according to the KACPR criteria for evaluating performance ability and were evaluated, with different items in each session. The researcher measured performance ability while positioned next to the manikin and the participant, as described in previous research [27]; correct performance ability received a score of 1 , and incorrect or no performance ability received a score of 0 , with the scores ranging from 0 to 11 .

To make the performance ability measurements more objective, an infant manikin's (PP-IM-100M, Prestan, Cleveland, $\mathrm{OH}, \mathrm{USA}$ ) click sound and LED display monitor were used to determine the chest pressure rate and depth accuracy. A definite click sound with correct chest pressure depth $(4 \mathrm{~cm})$ was scored as 1, and any other outcome was scored as 0; the presence of 2 green lights on the manikin's LED display monitor with the correct chest pressure rate (100 120 times/min) and intensity was scored as 1 and any other outcome was scored as 0 .

\section{Educational Intervention}

\section{1) Infant CPR training applying the 5-step method}

The training program for single-rescuer infant CPR used the 5-step method developed by George and Doto [12]. The educator-to-participant ratio was 1:10 or lower, and 10 participants were divided into small groups of 3 4 persons for verbalization and practice using the manikin. The participantto-manikin ratio was 1:4 or lower, and the training session lasted for 70 minutes.

To make an effective interventional strategy for infant CPR education, the draft version of the program was revised and supplemented by advice from 3 experts (a professor of pediatric nursing and 2 nurses in the Department of Pediatrics, who possessed CPR instructor licenses) on validity in terms of duration, content appropriateness, and procedural problems.

The researcher taught the program in each step after dividing it into general and group learning with the following content: The first step, lasting 10 minutes, aimed to motivate the participants, focusing on presenting the learning goals, obstacles to infant CPR performance ability, reinforcement factors, the general organization of the training program, and providing information about the materials used in the educational program. In particular, since the willingness of a witness to perform CPR is important, the program focused on overcoming the obstacles to infant CPR performance ability and on giving information about how to foster factors that re- 
inforce performance ability, such as the effects of CPR [28].

The second step focused on imitation. The participants were given an image describing how to perform infant CPR, and they were asked to watch a video on infant CPR (Heart saver First Aid CPR AED DVD Set 90-1028 4/11, American Heart Association, Dallas, TX, USA) without a separate explanation, with the objective of minimizing the side effects of variation in the educator's performance ability and skillfulness [4]. The second step lasted less than 5 minutes.

In the third step, infant CPR was divided into steps, representing the procedure for performing infant $\mathrm{CPR}$, and the video (Heart saver First Aid CPR AED DVD Set 90-1028 4/11, American Heart Association, Dallas, Texas, USA) was presented, with the educator explaining the chest pressure position and method and how to secure an airway on a theoretical basis. This step involved micro-skill learning, which is essential for novices because integrating the various skills involved in infant CPR poses a significant obstacle for them, whereas skilled persons are able to understand and perform the process as a whole [2]. The participants were permitted to ask questions in the pursuit of participant-educator interaction. The third step lasted 10 minutes, and the educator-participant ratio was 1:10 or lower during steps 1 3.

The fourth step involved verbalization of the procedure in small groups of 3 4 participants and lasted 15 minutes under the educator's supervision. The participants obtained a clear understanding of the procedure through verbalization as a way to acquire knowledge [13].

In the fifth step, learners practiced with an infant manikin (PP-IM-100M, Prestan, Cleveland, OH, USA), watching a video, under the educator's supervision. The manikin-to-student ratio was set at 1:3 or 1:4. Each student practiced 3 times, which lasted 30 minutes. The learners' errors were corrected immediately by the educator, because performing skills incorrectly can cause incorrect patterns to be consolidated, which makes them difficult to correct [2] (Table 1).

\section{2) Infant CPR training applying the traditional method (2-step method)}

This educational method was based on the 2011 KACPR [21], and lasted 50 minutes: 20 minutes of a theoretical lecture, followed by 30 minutes of video utilization. Participants practiced with an infant manikin (PP-IM-100M, Prestan, Cleveland, $\mathrm{OH}$, USA), while watching the infant CPR video (Heart saver First Aid CPR AED DVD Set 90-1028 4/11, American Heart Association, Dallas, Texas, USA). Nine to 10 students formed teams of three to four persons, and the manikin-tostudent ratio was set at 1:4 or lower. Each student practiced three times, which lasted 30 minutes in total. Errors were corrected by the educator after the session (Table 1).

\section{Data Collection}

This study was approved by the Institutional Review Board of E University in D city (**16-17). For ethical protection of the participants, they were provided an explanation of the research goals, methods, and confidentiality, and those willing to participate in the study were asked to provide informed consent before the study was conducted. Permission to use the measurement instruments was obtained from their developers through email.

Data collection was performed from April 25 to December 15,2016 . In the pretest and posttest, the researchers evaluated performance ability and used a questionnaire to measure knowledge and attitudes. The pretest was performed before the training session; the first posttest was performed 1 week after the training session, and the second posttest was performed 6 months after the training session. Since this study sought to investigate sustainability at a 6-month interval, changes such as dropouts and CPR license acquisition were taken into account. The second posttest was performed 6 months after the training session, when pediatric nursing clinical practice started in the second term, with no variation between the experimental and control groups. As an additional

Table 1. Comparison of the Infant Cardiopulmonary Resuscitation Training Programs Applied to the 2 Groups

\begin{tabular}{|c|c|c|c|c|}
\hline Step & $\begin{array}{c}\text { 5-Step } \\
\text { (experimental group) }\end{array}$ & $\begin{array}{l}\text { Time } \\
(\mathrm{min})\end{array}$ & $\begin{array}{l}\text { Traditional 2-step } \\
\text { (control group) }\end{array}$ & $\begin{array}{l}\text { Time } \\
(\mathrm{min})\end{array}$ \\
\hline I & Educator overview & 10 & \multirow{3}{*}{ Infant CPR explanation } & \multirow{3}{*}{20} \\
\hline II & Watching the video at the original speed & 5 & & \\
\hline III & $\begin{array}{l}\text { Watching the video of each step with a detailed } \\
\text { description }\end{array}$ & 10 & & \\
\hline IV & Verbal practice & 15 & & \\
\hline $\mathrm{V}$ & $\begin{array}{l}\text { Practicing under the educator's supervision, } \\
\text { including immediate feedback }\end{array}$ & 30 & Practicing with feedback from the educator & 30 \\
\hline
\end{tabular}

$\mathrm{CPR}=$ Cardiopulmonary resuscitation. 
curriculum item, this training session was not reflected in the participants' academic performance evaluations, and the control group was given additional education in the same way as the experimental group after the entire program ended.

The researcher measured performance ability in a distinct location, and each participant was guided by the research assistant into another separate location to prevent encounters with any waiting person when the measurement was completed. However, because a limitation of this study was the fact that the researcher participating in the education evaluated performance ability, the KACPR performance ability evaluation criteria and the infant manikin's (PP-IM-100M, Prestan, Cleveland, OH, USA) click sound and LED display monitor were used as evaluation tools to make performance ability measurements more objective.

This researcher had worked at an infant intensive care unit of a university hospital for 10 years, completed the infant cardiopulmonary resuscitation curriculum of the Korean Society of Neonatology in 2010, and completed the KACPR CPR curriculum in 2016.

\section{Data Analysis}

SPSS version 23 (IBM Corp., Armonk, NY, USA) was used to estimate the real number, percentage, and the mean and standard deviation for each general and CPR-related charac- teristic of the participants, and the $x^{2}$ test and t-test were performed to determine homogeneity. The t-test was performed to determine homogeneity among the dependent variables in the experimental and control groups; data were collected before and 1 week and 6 months after the intervention to determine the effects and sustainability of the training program and were analyzed using the t-test, repeated-measures ANOVA and ANCOVA with variance between the before and 1 week after the intervention as the covariate.

\section{RESULTS}

\section{Homogeneity of the Participants' General and CPR- related Characteristics}

The general and CPR-related characteristics of the experimental and control groups before performing infant CPR education using the 5-step method were tested for homogeneity, and the 2 groups were found to be homogeneous, with no significant differences (Table 2).

The mean age was $22.29 \pm 1.35$ years in the experimental group and $22.30 \pm 1.01$ years in the control group; the experimental group had 4 men $(14.3 \%)$ and 24 women $(85.7 \%)$, while the control group had 5 men $(15.1 \%)$ and 28 women $(84.9 \%)$. The participants' grade point average in the last term was $3.18 \pm 0.53$ in the experimental group and $3.17 \pm 0.55$ in the con-

Table 2. Homogeneity Test of General and Cardiopulmonary Resuscitation-related Characteristics and Dependent Variables between the Two Groups

$(N=61)$

\begin{tabular}{|c|c|c|c|c|c|}
\hline \multirow{2}{*}{ Variables } & \multirow{2}{*}{ Categories } & \multirow{2}{*}{$\frac{\text { Exp. }(n=28)}{n(\%) \text { or } M \pm S D}$} & \multirow{2}{*}{$\begin{array}{c}\text { Cont. }(\mathrm{n}=33) \\
\mathrm{n}(\%) \text { or } \mathrm{M} \pm \mathrm{SD}\end{array}$} & \multirow{2}{*}{$x^{2}$ or $\mathrm{t}$} & \multirow{2}{*}{$p$} \\
\hline & & & & & \\
\hline Age (year) & & $22.29 \pm 1.35$ & $22.30 \pm 1.01$ & 0.06 & .955 \\
\hline Gender & $\begin{array}{l}\text { Male } \\
\text { Female }\end{array}$ & $\begin{array}{r}4(14.3) \\
24(85.7)\end{array}$ & $\begin{array}{r}5(15.1) \\
28(84.9)\end{array}$ & & $>.999^{*}$ \\
\hline Grade point average & $\begin{array}{l}3.00 \sim 4.50 \\
1.00 \sim 2.99\end{array}$ & $\begin{array}{c}3.18 \pm 0.53 \\
18(64.3) \\
10(35.7)\end{array}$ & $\begin{array}{l}3.17 \pm 0.55 \\
20(60.6) \\
13(39.4)\end{array}$ & $\begin{array}{l}0.09 \\
0.08\end{array}$ & $\begin{array}{l}.922 \\
.797\end{array}$ \\
\hline Real experience of CPR & $\begin{array}{l}\text { Yes } \\
\text { No }\end{array}$ & $\begin{array}{r}3(13.8) \\
25(89.2)\end{array}$ & $\begin{array}{r}5(15.1) \\
28(84.9)\end{array}$ & & $.715^{*}$ \\
\hline $\begin{array}{l}\text { Experience of taking a CPR } \\
\text { course }\end{array}$ & $\begin{array}{l}\text { Yes } \\
\text { No }\end{array}$ & $\begin{array}{r}6(21.4) \\
22(78.6)\end{array}$ & $\begin{array}{r}7(21.2) \\
26(78.8)\end{array}$ & 0.01 & $>.999$ \\
\hline $\begin{array}{l}\text { Willingness to perform CPR } \\
\text { for family }\end{array}$ & $\begin{array}{l}\text { Yes } \\
\text { No }\end{array}$ & $\begin{array}{c}28(100.0) \\
0(0.0)\end{array}$ & $\begin{array}{c}30(90.9) \\
3(9.1)\end{array}$ & & $.243^{*}$ \\
\hline $\begin{array}{l}\text { Willingness to perform CPR } \\
\text { for stranger }\end{array}$ & $\begin{array}{l}\text { Yes } \\
\text { No }\end{array}$ & $\begin{array}{r}20(71.4) \\
8(28.6)\end{array}$ & $\begin{array}{r}28(84.9) \\
5(15.1)\end{array}$ & 1.63 & .227 \\
\hline Infant CPR & $\begin{array}{l}\text { Knowledge } \\
\text { Attitude } \\
\text { Performance ability }\end{array}$ & $\begin{array}{r}6.39 \pm 1.98 \\
69.36 \pm 9.17 \\
0.96 \pm 0.69\end{array}$ & $\begin{array}{r}6.91 \pm 2.84 \\
72.85 \pm 8.99 \\
1.03 \pm 1.18\end{array}$ & $\begin{array}{l}0.81 \\
1.49 \\
0.27\end{array}$ & $\begin{array}{l}.423 \\
.140 \\
.788\end{array}$ \\
\hline
\end{tabular}

*Fisher's exact test; Exp.=Experimental group (5-step method); Cont.=Control group (traditional, 2-step method); CPR=Cardiopulmonary resuscitation. 
trol group. In the experimental group, 18 participants (64.3\%) had a grade point average of $3.00 \sim 4.50$ and $10(35.7 \%)$ a grade point average of $1.00 \sim 2.99$, while the corresponding proportions were 20 participants (60.6\%) and 13 participants (39.4\%) in the control group, respectively. In the experimental group, 3 participants (13.8\%) had previous experience of giving CPR and $25(89.2 \%)$ had no such experience, while 5 participants (15.1\%) had experience performing CPR and 28 (84.9\%) had no such experience in the control group. Six participants (21.4 $\%$ ) had received CPR education and 22 (78.6\%) had not in the experimental group, while the corresponding proportions in the control group were 7 participants $(21.2 \%)$ and 26 participants (78.8\%), respectively. Twenty-eight participants (100\%) in the experimental group were willing to perform CPR in case of a family member experiencing cardiac arrest; in contrast, in the control group, $30(90.9 \%)$ were willing and $3(9.1 \%)$ were not. In the experimental group, 20 persons $(71.4 \%)$ were willing to perform CPR if a stranger experienced cardiac arrest, while 8 (28.6\%) were not; in contrast, the corresponding proportions in the control group were 28 participants $(84.9 \%)$ and 5 participants (15.1\%), respectively.

\section{Homogeneity of the Dependent Variables}

When the dependent variables in the experimental and control groups before infant CPR training applying the 5-step method were tested for homogeneity, the experimental group scored $6.39 \pm 1.98$ and $69.36 \pm 9.17$ and the control group scored $6.91 \pm 2.84$ and $72.85 \pm 8.99$ on average for knowledge and attitudes of infant CPR, respectively. The experimental group scored $0.96 \pm 0.69$ and the control group scored $1.03 \pm 1.18$ on average for infant CPR performance ability; thus, homogeneity was found between the 2 groups, with no statistically significant differences (Table 2).

\section{Hypothesis Testing}

Hypothesis 1, that the experimental group receiving infant
CPR training with the 5-step method would show higher scores for knowledge, attitudes, and performance ability than the control group at 1 week after the training program, was partially supported (Table 3). No statistically significant difference was found in the mean knowledge of infant CPR: the experimental group scored $6.39 \pm 1.98$ before the training program and $14.46 \pm 1.62$ at 1 week afterwards, and the control group scored $6.91 \pm 2.84$ before the training program and $13.94 \pm 1.85$ at 1 week afterwards. Statistically significant inter-group differences were found in participants' mean attitudes toward infant CPR, which increased by 11.29 from 69.36 \pm 9.17 before the training program to $80.64 \pm 9.59$ at 1 week afterwards in the experimental group and increased by 5.12 from $72.85 \pm 8.99$ before the training program to $77.97 \pm 8.56$ at 1 week afterwards in the control group $(t=2.68, p=.009)$. Statistically significant inter-group differences were found in mean infant CPR performance ability, which increased by 7.75 from $0.96 \pm 0.69$ before the training program to $8.71 \pm 1.48$ at 1 week afterwards in the experimental group, and increased by 6.00 from $1.03 \pm 1.18$ before the training program to $7.03 \pm 1.33$ at 1 week afterwards in the control group $(\mathrm{t}=4.56, p<.001)$.

Hypothesis 2, that the experimental group receiving infant CPR training with the 5-step method would maintain higher scores for knowledge, attitudes, and performance ability than the control group at 6 months after the training program, indicating the sustainability (the variation between 1 week and 6 months after the training program) of its effects, was partially supported (Table 4). No statistically significant difference between the experimental and control groups was found in the sustainability of changes in knowledge of infant CPR, which differed significantly by the 3 measurement times (before the training program and 1 week and 6 months after the training program) ( $\mathrm{F}=309.34, p<.001)$, with no significant interaction between the experimental and control groups and the 3 measurement times. No statistically significant difference between the educational and control groups was found in the sustainability of changes in attitude toward infant CPR, which differed statistically significantly by the 3 measurement time $(\mathrm{F}=$

Table 3. Mean Difference between before and Week 1 of Infant Cardiopulmonary Resuscitation Training in the Two Groups ( $N=61)$

\begin{tabular}{|c|c|c|c|c|c|c|c|}
\hline \multirow{2}{*}{ Variables } & \multirow{2}{*}{ Group } & \multirow{2}{*}{$\mathrm{n}$} & Pre & Post & Difference & \multirow{2}{*}{$\mathrm{t}$} & \multirow{2}{*}{$p$} \\
\hline & & & $\mathrm{M} \pm \mathrm{SD}$ & $\mathrm{M} \pm \mathrm{SD}$ & $\mathrm{M} \pm \mathrm{SD}$ & & \\
\hline \multirow[t]{2}{*}{ Knowledge } & Exp. & 28 & $6.39 \pm 1.98$ & $14.46 \pm 1.62$ & $8.07 \pm 2.26$ & \multirow[t]{2}{*}{1.63} & \multirow[t]{2}{*}{.108} \\
\hline & Cont. & 33 & $6.91 \pm 2.84$ & $13.94 \pm 1.85$ & $7.03 \pm 2.65$ & & \\
\hline \multirow[t]{2}{*}{ Attitude } & Exp. & 28 & $69.36 \pm 9.17$ & $80.64 \pm 9.59$ & $11.29 \pm 9.06$ & \multirow[t]{2}{*}{2.68} & \multirow[t]{2}{*}{.009} \\
\hline & Cont. & 33 & $72.85 \pm 8.99$ & $77.97 \pm 8.56$ & $5.12 \pm 8.87$ & & \\
\hline \multirow[t]{2}{*}{ Performance ability } & Exp. & 28 & $0.96 \pm 0.69$ & $8.71 \pm 1.48$ & $7.75 \pm 1.48$ & \multirow[t]{2}{*}{4.56} & \multirow[t]{2}{*}{$<.001$} \\
\hline & Cont. & 33 & $1.03 \pm 1.18$ & $7.03 \pm 1.33$ & $6.00 \pm 1.50$ & & \\
\hline
\end{tabular}

Exp.=Experimental group (5-step method); Cont.=Control group (traditional, 2-step method); Pre=Before infant cardiopulmonary resuscitation training; Post=At 1 week after infant cardiopulmonary resuscitation training. 
Table 4. Effects of Infant Cardiopulmonary Resuscitation Training Sustainability in the Two Groups

$(N=61)$

\begin{tabular}{|c|c|c|c|c|c|c|c|}
\hline \multirow{2}{*}{ Variables } & \multirow{2}{*}{ Categories } & \multirow{2}{*}{$\begin{array}{c}\text { Exp. }(n=28) \\
M \pm S D\end{array}$} & \multirow{2}{*}{$\begin{array}{c}\text { Cont. }(\mathrm{n}=33) \\
\mathrm{M} \pm \mathrm{SD}\end{array}$} & \multirow{2}{*}{ tor $F$} & \multirow{2}{*}{$p$} & & \multirow{2}{*}{$\mathrm{F}(p)$} \\
\hline & & & & & & & \\
\hline \multirow[t]{6}{*}{ Knowledge } & $\mathrm{T} 1$ & $6.39 \pm 1.98$ & $6.91 \pm 2.84$ & 0.80 & .423 & Time & $309.34(<.001)$ \\
\hline & $\mathrm{T} 2$ & $14.46 \pm 1.62$ & $13.94 \pm 1.85$ & 1.16 & .248 & Group*Time & $2.39(.095)$ \\
\hline & $\mathrm{T} 3$ & $12.57 \pm 1.68$ & $11.79 \pm 2.47$ & 1.46 & .149 & Group & $0.40(.529)$ \\
\hline & $\mathrm{T} 2 \sim \mathrm{T} 1$ & $8.07 \pm 2.26$ & $7.03 \pm 2.65$ & 1.63 & .108 & & \\
\hline & $\mathrm{T} 3 \sim \mathrm{T} 1$ & $6.18 \pm 2.26$ & $4.88 \pm 3.06$ & 1.86 & .068 & & \\
\hline & $\mathrm{T} 3 \sim \mathrm{T} 2$ & $-1.89 \pm 2.01$ & $-2.15 \pm 2.16$ & 0.48 & .633 & & \\
\hline \multirow[t]{6}{*}{ Attitudes } & $\mathrm{T} 1$ & $69.36 \pm 9.17$ & $72.85 \pm 8.99$ & 1.49 & .140 & Time & $33.72(<.001)$ \\
\hline & $\mathrm{T} 2$ & $80.64 \pm 9.59$ & $77.97 \pm 8.56$ & 1.15 & .254 & Group*Time & $4.32(.015)$ \\
\hline & $\mathrm{T} 3$ & $71.36 \pm 7.18$ & $69.42 \pm 7.70$ & 1.01 & .318 & Group & $0.04(.833)$ \\
\hline & $\mathrm{T} 2 \sim \mathrm{T} 1$ & $11.92 \pm 9.01$ & $5.12 \pm 8.87$ & 2.68 & .009 & & \\
\hline & $\mathrm{T} 3 \sim \mathrm{T} 1$ & $2.00 \pm 9.05$ & $-3.42 \pm 10.07$ & 2.19 & .032 & & \\
\hline & $\mathrm{T} 3 \sim \mathrm{T} 2$ & $-9.29 \pm 8.70$ & $-8.55 \pm 7.58$ & 3.55 & .724 & & \\
\hline \multirow[t]{6}{*}{ Performance ability } & $\mathrm{T} 1$ & $0.96 \pm 0.69$ & $1.03 \pm 1.18$ & 0.25 & .796 & Time & $689.14(<.001)$ \\
\hline & $\mathrm{T} 2$ & $8.71 \pm 1.48$ & $7.03 \pm 1.33$ & 4.66 & $<.001$ & Group*Time & $12.45(.002)$ \\
\hline & $\mathrm{T} 3$ & $4.96 \pm 1.79$ & $3.85 \pm 1.90$ & 2.34 & .023 & Group & $13.99(<.001)$ \\
\hline & $\mathrm{T} 2 \sim \mathrm{T} 1$ & $7.75 \pm 1.48$ & $6.00 \pm 1.50$ & 4.56 & $<.001$ & & \\
\hline & $\mathrm{T} 3 \sim \mathrm{T} 1$ & $4.00 \pm 2.00$ & $2.82 \pm 1.77$ & 2.44 & .018 & & \\
\hline & $\mathrm{T} 3 \sim \mathrm{T} 2$ & $-3.75 \pm 2.08$ & $-3.18 \pm 2.49$ & $6.76^{*}$ & .012 & & \\
\hline
\end{tabular}

*Covariate value=T2 T1; Exp.=Experimental group (5-step method); Cont.=Control group (traditional, 2-step method); T1=Pretest (before infant cardiopulmonary resuscitation training); T2=Post test 1 ( 1 week after infant cardiopulmonary resuscitation training); T3=Posttest 2 (6 months after infant cardiopulmonary resuscitation training).

$33.72, p<.001)$, with significant interaction between the experimental and control groups and the 3 measurement times $(\mathrm{F}=4.32, p=.015)$. However, statistically significant inter-group differences were found in the sustainability of improvements in infant CPR performance ability between the experimental and control groups $(\mathrm{F}=13.99, p<.001)$ and by the 3 measurement time $(\mathrm{F}=698.14, p<.001)$, with significant interaction between the experimental and control groups and the 3 measurement times $(\mathrm{F}=12.45, p=.002)$. The groups were not homogeneous, with statistically significant inter-group differences in performance ability at 1 week after the training program $(\mathrm{t}=4.66, p<.001): 8.71 \pm 1.48$ in the experimental group and $7.03 \pm 1.33$ in the control group. With the differences in the scores for performance ability between before and 1 week after the training program as covariates (T2-T1), statistically significant inter-group differences were found in performance ability at 6 months after the training program $(\mathrm{F}=6.76, p=.012)$

\section{DISCUSSION}

This study aimed to develop an infant CPR training program for nursing students by applying the 5-step method developed by George and Doto [12] and to test its effectiveness.

The nursing students who received infant CPR training applying the 5-step method showed better performance ability than those who were trained using the traditional method (2-step), and the improvements in their performance ability were sustained at 6 months later. While no study has yet applied the 5-step method to CPR, an international study applied it to dental care students' application of fissure sealant, and more than $90 \%$ of the skill remained at 18 months after the training program 6 [1]. Medical students given clinical skill training using the 5-step method showed significantly better performance ability and confidence [29]. This finding demonstrates that the 5-step method is effective in improving performance ability, supporting the results of this study. While any type of educational method is effective immediately after education, it is believed that the third step (in which novices could acquire micro-skills) and the fifth step (in which the educator could give immediate feedback after any error) were especially helpful to the learners.

Contrary to this study, a previous study found no significant difference between the 5-step method and the traditional education method (2-step) in medical students' ability to perform manual defibrillation 2 months later [17]. The discrepancy between that finding and the results of our study is most likely due to differences in educators' and colleagues' ability to provide feedback. Feedback from colleagues, as was used in that study due to limited staffing in the educational environment, could be less accurate than feedback from the educa- 
tor, and it could be difficult for students to indicate their colleagues' errors thoroughly; therefore, feedback from colleagues could be less effective than feedback from the educator, resulting in the lack of sustained improvements in performance. It is therefore desirable for a skilled educator to give nursing students concrete and accurate guidance with the objective of improving and sustaining infant CPR performance ability.

However, even in this infant CPR training program that applied the 5-step method, performance ability decreased by about $11 \%$ at 6 months after training. A previous study applying immediate remediation to infant CPR education for childcare teachers found that their performance ability decreased by about $24 \%$ at 6 months after training [6]. Despite differences in trainees and methods, this study and the previous one [6] obtained the same basic result: the effects of education decreased with time. This finding therefore demonstrates the need for educational refreshers, at least for childcare teachers, healthcare providers, and preservice healthcare providers, such as nursing and medical students, on a timely basis using a differentiated method. In particular, performance ability can decrease more rapidly than knowledge in terms of infant CPR [30]; therefore, it is essential to provide a repeated training session within 6 months in terms of sustainability of performance ability.

The nursing students who received infant CPR training applying the 5-step method showed more positive changes in their attitudes than those who received training using the traditional method (2-step), which failed to be sustained 6 months later. The literature review found that health-related college students who received training on adult, child, and infant CPR using the traditional education method (2-step) for 8 hours experienced positive changes in attitudes [9]. Nurses given a combination of CPR education using the traditional educational method (2-step) and debriefing for 3 hours experienced positive changes in attitudes immediately after the training program [5]. It is therefore clear the traditional educational method (2-step) can positively change attitudes toward CPR immediately after education. It is believed, however, that the first step of the 5-step method focusing on infant CPR reinforcement and obstacles positively changed attitudes toward infant CPR, which is consistent with the finding that education related to those attitudes reinforced willingness to perform CPR [28]. However, the scores for attitudes at 6 months after the training decreased to the level before the training, which is consistent with the finding that positive attitudes could decrease with time, regardless of educational methods [5]. The 5-step method is effective in changing attitudes positively, but it cannot prevent positive attitudes from decreasing over time; therefore, it is necessary to provide a re- peated training session within 6 months.

Both the nursing students who received infant CPR training using the 5-step method and who received infant CPR training using the traditional education method (2-step) saw their knowledge increase by about $50 \%$ at 1 week after the training program, compared with before the education, and then to decrease by about $30 \%$ at 6 months after the training program, compared with 1 week afterwards. Similar to this study, our literature review found that immediate remediation characterized by the educator's additional demonstration and repeated feedback [7] and a video-self instruction program [8] increased knowledge of infant or child CPR, but with no significant difference from any traditional teaching method. This finding seems to indicate that this new educational method is not significantly effective in increasing knowledge. Nonetheless, the 5-step method, which involves no separate theoretical lecture or video-self instruction for learners' self-study can increase knowledge, which demonstrates that education based on a lecture by the educator is not essential for improving knowledge of CPR.

Putting these results together, infant CPR training applying the 5-step method was effective in changing of nursing students' attitudes positively and improving their performance ability immediately after the training program. Additionally, infant CPR training applying the 5-step method was effective in sustainability of nursing students' performance ability until 6 months, even though their performance ability was reduced. It is believed that this occurred because the 5-step method involved interactions between a skilled educator and the learner. However, the effects of education decreased with time; therefore, it is necessary to provide a repeated training session within 6 months. Furthermore, knowledge and attitudes were not effective over time even when the 5-step method was applied; therefore, it is necessary to provide a repeated training session within 6 months. This study is significant in that, first, it was the first study to perform the experiment of applying the 5-step method in nursing students and presented groundwork for conducting further research on effective and sustainable methods of infant CPR training; second, it allowed nursing students to understand the importance and need of infant $\mathrm{CPR}$, which is not included in the curriculum; third, it re-emphasized the educator's role and the importance of direct instruction in an educational situation where exchanges between the educator and learner are becoming less common.

This study has certain limitations. First, the possibility of experiment spreading could not be excluded both because both the experimental and control groups contained students at the same university and because the study used a nonsynchronized design due to the participants' academic schedule. In addition, at the time of the study, the Korean version 
of the American Heart Association CPR Healthcare Provider guidelines had not been published, so knowledge and performance were measured by the researchers' tools based on the 2011 KACPR [21]. Therefore, a difference between actual knowledge and performance ability can be expected to exist. Lastly, care should be taken in generalizing the results of this study, which was conducted among nursing students at a single university; the low reliability of the attitude instrument due to the small sample size and single-university setting are considered relevant in terms of the limited ability of the study results to be generalized.

\section{CONCLUSION}

This study aimed to develop an infant CPR training program applying the 5-step method, which presents a clear role of the educator within the learning process, for nursing students. The experimental group showed higher scores for infant CPR attitude and performance ability than the control group. At 6 months after the training program, knowledge, attitudes, and performance ability had decreased in both the experimental group and the control group. However, the performance ability level was higher in the experimental group than in the control group, showing that the 5-step method was more effective than the traditional education method. However, as time passes, the effectiveness of the education decreases, and it is considered that a repeated training session is necessary within 6 months. Through this study, groundwork has been established for the educator's role and the importance of direct instruction in infant CPR training and the appropriate interval for repeated trainings.

On the basis of these results, the following suggestions can be made: First, it is necessary to reinforce and operate infant CPR training as part of clinical practice in the curriculum of nursing colleges. Second, it is necessary to define the correct time for sustaining infant CPR expertise developed by using the 5-step method. Third, research should be conducted to determine learning satisfaction among those who received the training program applying the 5-step method.

\section{Conflict of interest}

No existing or potential conflict of interest relevant to this article was reported.

\section{REFERENCES}

1. Park CB, Shin SD, Suh GJ, Ahn KO, Cha WC, Song KJ, et al. Pediatric out-of-hospital cardiac arrest in Korea: A nationwide population-based study. Resuscitation. 2010;81(5):512-517. https://doi.org/10.1016/j.resuscitation.2009.11.022

2. Jung JW. Procedures: Essential and optional. 2015 The Korean society of emergency medicine fall symposium; 2015 Oct; Songdo Convensia. Incheon: Symposium Abstracts The Korean Society of Emergency Medicine; 2015. p. 253-255.

3. Kaczorowski J, Levitt C, Hammond M, Outerbridge E, Grad R, Rothman A, et al. Retention of neonatal resuscitation skills and knowledge: A randomized controlled trial. Family Medicine. 1998; 30(10):705-711.

4. Yang HJ, Kim GW, Cho GC, Tak YJ, Chung SP, Hwang SO. Part 8. Cardiopulmonary resuscitation education: 2015 Korean guidelines for cardiopulmonary resuscitation. Clinical and Experimental Emergency Medicine. 2016;3(Suppl):S66-S68. https://doi.org/10.15441/ceem.16.136

5. Byun GR, Park JE, Hong HS. The effects of video programs of cardiopulmonary cerebral resuscitation education. Journal of Korean Biological Nursing Science. 2015;17(1):19-27. https://doi.org/10.7586/jkbns.2015.17.1.19

6. Kim IO, Shin SH. The CPR educational program effect of infant CPR immediate remediation for child care teachers. The Journal of Korean Academic Society of Nursing Education. 2013;19(4):508-517. https://doi.org/10.5977/jkasne.2013.19.4.508

7. Kim IO, Shin SH. The effect of the infant cardiopulmonary resuscitation immediate remediation for child care teachers. Journal of Korean Academic Society of Nursing Education. 2015;21(3):350360. https:// doi.org/10.5977/jkasne.2015.21.3.350

8. Kim GH. The effects of child cardiopulmonary resuscitation education for childcare teachers with a video self-instruction program. The Journal of the Korean Society of Emergency Medical Technology. 2009;13(2):87-98.

9. Kwon MS. The effects of basic life support course for healthcare providers on the knowledge and attitude of health science college students. Journal of the Korea Academia-Industrial cooperation Society. 2012;13(12):5943-5949.

https://doi.org/10.5762/KAIS.2012.13.12.5943

10. Kim HS, Kim MS, Park MH. Analysis of nursing students' knowledge, attitude and ability to perform cardiopulmonary resuscitation. Journal of the Korean Academy Fundamentals of Nursing. 2009;16(4):430-437.

11. Simpson E. Educational objectives in the psychomotor domain. In: Kapfer MB, editor. Behavioral objectives in curriculum development: Selected readings and bibliography. Englewood Cliffs, NJ: Educational Technology; 1971. p. 60.

12. George JH, Doto FX. A simple five-step method for teaching clinical skills. Family Medicine. 2001;33(8):577-578.

13. Figueiredo AE, Bernardini J, Bowes E, Hiramatsu M, Price V, Su C, et al. A syllabus for teaching peritoneal dialysis to patients and caregivers. Peritoneal Dialysis International. 2016;36(6):592-605. https://doi.org/10.3747/pdi.2015.00277

14. Oermann MH, Muckler VC, Morgan B. Framework for teaching 
psychomotor and procedural skills in nursing. The Journal of Continuing Education in Nursing. 2016;47(6):278-282.

https://doi.org/10.3928/00220124-20160518-10

15. Issenberg SB, Mcgaghie WC, Petrusa ER, Gordon DL, Scalese RJ. Features and uses of high-fidelity medical simulations that lead to effective learning: A BEME systematic review. Medical Teacher. 2005;27(1):10-28. https://doi.org/10.1080/01421590500046924

16. Virdi MS, Sood M. Effectiveness of a five-step method for teaching clinical skills to students in a dental college in India. Journal of Dental Education. 2011;75(11):1502-1506.

17. Archer E, van Hoving DJ, de Villiers A. In search of an effective teaching approach for skill acquisition and retention: Teaching manual defibrillation to junior medical students. African Journal of Emergency Medicine. 2015;5(2):54-59. https://doi.org/10.1016/j.afjem.2014.10.009

18. Yang YJ, Kwon IS. Nursery teachers' knowledge, attitude and performance ability in cardiopulmonary resuscitation. Child Health Nursing Research. 2014;20(4):304-313. https://doi.org/10.4094/chnr.2014.20.4.304

19. Faul F, Erdfelder E, Buchner A, Lang AG. Statistical power analyses using G Power 3.1: Tests for correlation and regression analyses. Behavior Research Methods. 2009;41(4):1149-1160. https://doi.org/10.3758/BRM.41.4.1149

20. Kang HC, Yeon KP, Han ST. A review on the use of effect size in nursing research. Journal of Korean Academic Nursing. 2015;45(5): 641-649. https://doi.org/10.4040/jkan.2015.45.5.641

21. Hazinski MF, Hwang SO. editors. Basic life support provider manual. Mesquite, Texas: American Heart Association; 2013.

22. Lee KY, Kim CJ. Analysis of Korea earth science olympiad items for the enhancement of item quality. The Journal of The Korean Earth Science Society. 2005;26(6):511-523.

23. Polit DF, Beck CT. The content validity index: Are you sure you know what's being reported? critique and recommendations. Research in Nursing and Health. 2006;29(5):489-497.

https://doi.org/10.1002/nur.20147

24. Cho HY. Analysis of nurses' attitude toward basic life support and influencing factors [master's thesis]. Seoul: Yonsei University; 2008. p. 1-80.

25. Park JS, Jeon HR. The effect of basic life support education using a standardized basic life support video program in nurses' cardiopulmonary resuscitation knowledge, attitude and performance. The Journal of Korean Academic Society of Nursing Education. 2010;16(2):301-311. https://doi.org/10.5977/JKASNE.2010.16.2.301

26. Kim K. Likert scale. Korean Journal of Family Medicine. 2011;32 (1):1-2. https://doi.org/10.4082/kjfm.2011.32.1.1

27. Jones A, Lin Y, Nettel-Aguirre A, Gilfoyle E, Cheng A. Visual assessment of CPR quality during pediatric cardiac arrest: Does point of view matter? Resuscitation. 2015;90:50-55. https://doi.org/10.1016/j.resuscitation.2015.01.036

28. Jung HK, Uhm TH. Factors that influence kindergarten teachers' willingness to perform cardiopulmonary resuscitation. The Korean Journal of Emergency Medical Services. 2015;19(2):19-27. https://doi.org/10.14408/kjems.2015.19.2.019

29. Murdoch Eaton D, Cottrell D. Structured teaching methods enhance skill acquisition but not problem-solving abilities: An evaluation of the 'silent run through'. Medical Education. 1999;33(1): 19-23.

30. Shavit I, Peled S, Steiner IP, Harley DD, Ross S, Tal-Or E, et al. Comparison of outcomes of two skills-teaching methods on lay-rescuers' acquisition of infant basic life support skills. Academic Emergency Medicine. 2010;17(9):979-986. https://doi.org/10.1111/j.1553-2712.2010.00849.x 